This item was submitted to Loughborough's Research Repository by the author.

Items in Figshare are protected by copyright, with all rights reserved, unless otherwise indicated.

\title{
Modeling and simulating hospital operations in a 3D environment
}

PLEASE CITE THE PUBLISHED VERSION

https://doi.org/10.1109/WSC.2017.8248017

PUBLISHER

(c) IEEE

VERSION

AM (Accepted Manuscript)

LICENCE

CC BY-NC-ND 4.0

REPOSITORY RECORD

Greenroyd, Fraser L., Andrew D.F. Price, Peter Demian, Rebecca Hayward, and Shrikant Sharma. 2019. "Modeling and Simulating Hospital Operations in a 3D Environment". figshare.

https://hdl.handle.net/2134/27918. 


\title{
MODELING AND SIMULATING HOSPITAL OPERATIONS IN A 3D ENVIRONMENT
}

\author{
Fraser L. Greenroyd \\ Andrew Price \\ Peter Demian \\ School of Civil and Building Engineering \\ Loughborough University \\ Loughborough \\ Leicestershire LE11 3TU, UK
}

\author{
Rebecca Hayward \\ Shrikant Sharma \\ Smart Space Team \\ BuroHappold Engineering Ltd. \\ Bath \\ Somerset BA2 3DQ, UK
}

\begin{abstract}
The use of dashboards to aid hospital decision makers in managerial and clinical decisions is well documented in the literature, though few broach the challenging subject of combining cost measurement with user satisfaction and building layout optimization. This paper presents an innovative dashboard in a 3D environment, providing decision makers with simulation capabilities using agent based simulation, allowing examination of their facility and the impact of policy, process and layout changes on patients and finances. An example is presented for an Emergency Department, wherein the presented dashboard revealed that the costs of constructing additional triage rooms would produce no benefit to patients; rather, a change in the process would be more beneficial compared with the existing situation. It is concluded that the developed dashboard allows users to make comparisons between multiple scenarios and visualize data in an intuitive format, allowing for decision makers to optimize their facility and operations.
\end{abstract}

\section{INTRODUCTION}

Healthcare is a complex array of interconnected functions aimed at prolonging quality of life in a population and hospitals face a wide range of issues in seeking to provide high quality care in an affordable manner. The National Health Service (NHS) England is viewed as being among the best health systems in the western world (Davis et al. 2014), yet it struggles with changing demographics putting pressure on the services provided (Department of Health 2013; NHS England 2013b). In recent times, the pressure on the NHS has been increasingly financial. In 2009, the NHS was issued the 'Nicholson challenge' to find £20bn of efficiency savings by 2015 (Nicholson 2009). This was not met and in 2016 the UK Government issued the NHS a fresh target to make $£ 5 \mathrm{bn}$ of efficiency savings per annum between 2016 and 2020 (Carter 2016).

Of the $£ 5$ bn per annum target, $£ 1$ bn is estimated to be capable of being saved through improved estates and facilities management (Carter 2016) by removing unwarranted variations between healthcare providers. As part of this, it has been recommended that NHS Trusts use a productivity dashboard, developed as part of the Carter Report (2016), to obtain an understanding of their individual estates' costs, and areas where they can improve to fall in line with their peers (Carter 2016). Similar dashboards have been used before to measure a variety of healthcare performance in an attempt to provide manageable information to healthcare providers.

Dashboards are used in a variety of sectors to aid the understanding and application of data. They have been frequently developed for business managers to integrate and summarize data and key performance information in a visual display (Dowding et al. 2015). Previous healthcare related dashboards have been developed to analyze bed occupancies (Daley et al. 2013), readmission prevention 
(Stadler et al. 2016) and performance management (Mesabbah and Arisha 2016). Other dashboards have been built as Discrete-Event Simulators (DES) to estimate capacity levels (Werker et al. 2009), measure policy impact (Fletcher et al. 2007), simulate patient scheduling (Lee et al. 2013; Werker et al. 2009; Quevedo and Chapilliquén 2015; Harper and Gamlin 2003) and aid strategic decision making (Leskovar et al. 2011; Vanberkel and Blake 2007; Ballard and Kuhl 2006).

The metrics used by dashboards in a healthcare setting vary greatly depending on the use of the dashboard. Those that give focus to patient scheduling tend to focus on outputs related to utilization and patient waiting (for example, Lee et al. (2013); Al-Araidah et al. (2012)), while those that focus on hospital management tend to measure bed occupancy and patient length of stay or readmissions (for example, Daley et al. (2013); Stadler et al. (2016)).

Dashboards are typically built in a way to convey important information easily without the risk of misinterpretation. The presentation of information from such tools should be done in a way that allows users to easily understand the outputs in a format that transcends language barriers (Petersen 2002). Petersen (2002) suggested common output formats include the use of blue/green/yellow/red colors to indicate temperature (ranging from low, cold (blue) to high, hot (red)), and the use of traffic light systems (red/yellow/green) for outputs ranging on a bad to good scale. The ability to view the right level of detail for the right user is also vital to ensure the right information is dealt with by the right people (Pauwels et al. 2009). Too much data can be overwhelming to users, with usability and utility of a tool being easily lost in noise from too much data (Stadler et al. 2016). Similarly, the time taken to obtain value from data can be prohibitive if the tools do not present the data in an easy to understand format (Stadler et al. 2016; Halford et al. 2005). It has been argued by Halford et al. (2005) that accuracy of interpretation decreases when the complexity of the tool increases.

There are typically two types of dashboard utilized in the healthcare sector, clinical and quality (Dowding et al. 2015). Clinical dashboards are defined by Dowding et al. (2015) as information technology which gives an output of productivity or quality indicators in a visual manner. They allow clinicians to access data in a timely manner to inform health decisions which may impact patient care (Dowding et al. 2015). Examples of clinical dashboards are seen in McMenamin, Nicholson, and Leech (2011), Koopman et al. (2011), and Waitman et al. (2011). Quality dashboards, however, provide productivity and quality indicators to managers in a visual manner, enabling decision makers in healthcare organizations to identify aspects that can be improved for efficiency, patient care or cost (Dowding et al. 2015). Examples of quality dashboards include Fletcher et al. (2007), Lee et al. (2013), and Al-Araidah, Boran, and Wahsheh (2012).

\section{LITERATURE REVIEW}

A review of recent publications describing dashboards shows the vast range of technologies in use that aim to aid healthcare operations, ranging from web-based (Waitman et al. 2011), to custom developments utilizing FoxPro (Batley et al. 2011) and creating add-ons for existing systems (Koopman et al. 2011). Of these tools, the data output provided to users is consistent, aiming to give actionable intelligence to clinicians and managers for the best patient care. Many make use of 'traffic-light' output to highlight areas which need review, for example: when an item needs an update (McMenamin, Nicholson, and Leech 2011); highlighting that a new result is available (Batley et al. 2011); or indicating whether a patient's record has been reviewed that day (Waitman et al. 2011). Other common features include the use of graphs to present information to the users, as seen in the dashboards presented by Waitman et al. (2011) and Daley et al. (2013).

The development of dashboards is diverse and they are generally built to serve a specific purpose for a specific facility, rather than as a generic tool to aid facility management. This is seen in the dashboards presented by McMenamin et al. (2011), Koopman et al. (2011), Batley et al. (2011), Waitman et al. (2011) and Daley et al. (2013). The dashboard presented by McMenamin, Nicholson, and Leech (2011) is built as a clinical reminder system for general practice clinics in Whanganui (New Zealand), providing 


\section{Greenroyd, Hayward, Price, Demian, and Sharma}

clinicians with information related to agreed health targets for patients. The effects of the dashboard on practice included an increase in the data collection for alcohol intake and smoking use among patients, along with an increase in cervical, breast and diabetes screening as well as cardiovascular risk assessments (McMenamin, Nicholson, and Leech 2011). The dashboard by Koopman et al. (2011) was created as an add-on to electronic health records for diabetes patients and avoided repeating tests as patient information was collated in an easy to understand format, improving the speed with which it could be accessed by clinicians (Koopman et al. 2011).

Batley et al. (2011) produced a dashboard utilizing FoxPro on Microsoft XP machines, linking various systems together to provide data for clinicians. The tool used a traffic-light system to highlight which results had been reviewed (green) and which were new (red). Key to the reported success of the dashboard was the interface design, with the study highlighting how a usable design can aid the adoption of a new system (Batley et al. 2011). The dashboard presented by Waitman et al. (2011) also used a color coding system to alert users to whether a patient record had been reviewed that day (green) or whether it needed review (red). The use of this color system was coupled with charts to provide pharmacists with alerts to potential drug dispensing errors to patients with a given background. This allowed pharmacists to intercept medication errors and reduce adverse drug events (Waitman et al. 2011). Daley et al. (2013) similarly showed that utilizing a set of clear visual displays in a dashboard layout can improve information-sharing and awareness between users and improve the quality of data for decision making.

These dashboards display existing data to provide insights and represent information using charts, colors and other visual aids to aid decision making by users for clinical care or management. However, there are also dashboards which use simulation technologies to inform, guide and predict how clinical care and facility management may be impacted in a variety of scenarios. These have included studies looking at: improving radiation therapy planning (Werker et al. 2009); reducing waiting times and delays (Harper and Gamlin 2003; Vanberkel and Blake 2007; Al-Araidah, Boran, and Wahsheh 2012); modelling outpatient departments (Quevedo and Chapilliquén 2015); modelling emergency departments (Zeng et al. 2012; Cabrera et al. 2012; Brenner et al. 2010); maximizing utilization and capacities (Lee et al. 2013; Ballard and Kuhl 2006); and measuring the impact of policy changes (Fletcher et al. 2007).

These studies employ a range of simulation tools to achieve the core functionality of their simulation dashboards, such as agent-based modelling (Cabrera et al. 2012), SIMUL8 (Harper and Gamlin 2003; Brenner et al. 2010; Zeng et al. 2012) and Arena (Werker et al. 2009; Ballard and Kuhl 2006; Vanberkel and Blake 2007; Quevedo and Chapilliquén 2015; Al-Araidah, Boran, and Wahsheh 2012). SIMUL8 and Arena offer similar discrete-event simulation capabilities for complex systems analysis, such as drug dispensing and patient flows, with Arena additionally providing an option to visualize results in a 3D environment via a dashboard utilizing charts to visualize results as they are generated. Simulations can be used to predict a range of changes to layout or throughput. Vahdatzad and Griffin (2016), for example, produced a simulation model to optimize a facility layout between pod-based and sharing-based clinical room layouts, which advocates for the use of simulating multiple options when building healthcare spaces to aid decision making.

However, such dashboards typically focus on a specific problem for a specific facility or department of a hospital. Few incorporate a direct financial cost of, for example, the floor space of the facility, rather, they include a reference to the cost of the care in terms of patients seen or re-admittance. Similarly, most dashboard tools are built for use by clinicians for patient health decision making, rather than for facilities' managers for facility-based decision making. They operate using primarily discrete-event simulation technologies with few utilizing 3D representations as the norm. As the NHS is increasingly forced to focus on both the costs of care in terms of space utilization and floor area, and patient safety and experience in terms of waiting times and quality of care, there is a gap for a dashboard that can be used by managers to analyze and predict a facility's performance. This paper introduces the Hospital Operations Modelling (HOM) dashboard, which can be used by facility managers in a 3D environment to: visualize 
existing scenarios; predict the impact of future demand with agent based simulation; and manage layout changes and analyze the impact they have on costs, patients waiting and facility utilization.

\section{THE HOSPITAL OPERATIONS MODELLING (HOM) DASHBOARD}

The dashboard tool itself has been built as a plugin for Rhinoceros 3D, a 3D modelling tool used by architects and engineers to design and analyze building models. It is the primary environment utilized by SmartMove, an agent-based simulation tool developed by BuroHappold for use in people flow consultancy (Varughese et al. 2010; Sharma and Fisher 2013). SmartMove has been previously used to analyze the potential performance change in a pharmacy department (Greenroyd et al. 2016), however, the tool is a specialized people flow tool used by people flow consultants and is unlikely to be used by healthcare managers. On its own, SmartMove is capable of simulating a given layout and a given number of scenarios, but can be cumbersome to the inexperienced user.

Generalizability of the HOM dashboard was a key objective in its development. Rather than having one fixed dashboard that all users must comprehend, this dashboard is made up of several widgets which users can opt to display or hide based on their individual preference. This gives the dashboard significant flexibility in terms of layout and functionality. Each capability of the dashboard is self-contained within its own widget, with the user able to search for new widgets or remove widgets as they deem necessary.

The HOM dashboard utilizes the powerful agent-based simulation modelling capabilities of SmartMove to provide simulation options to the dashboard. This is coupled with widgets for managing different layouts and displaying results back to the user. The ability to manage several layouts offers users the capability to modify their facility and then re-simulate a scenario to assess the impact of that layout change on patients and staff. For example, a manager may change the layout to include an additional triage room for an emergency department, or to close a corridor to prevent infection spread. These layout changes can be applied and saved to the dashboard to be selected for simulation and analysis.

The self-contained widgets make it easy for users to change the model being analyzed. The activities widget allows users to increase or decrease rooms with a single button click, or create new activity definitions quickly. The layouts widget allows users to modify the department or facility layout by adding, moving or removing walls. Multiple layouts can be drawn and saved for simulation, allowing many options to be considered and presented to stakeholders.

Displaying results is spread across a collection of widgets to allow the user to select the result display most relevant to them. This includes a chart widget, which allows the user to select from a range of metrics and plot the data in an understandable format. Metrics include: occupancy of the whole facility or of a specific area (e.g. a waiting area); waiting times (average (mean) or maximum); and utilization (average (mean) or current). A cost function widget is also provided, allowing users to see how much the layout will cost per group of rooms (e.g. how much three triage rooms cost compared with five triage rooms) and how much the facility as a whole will cost (sum of all defined activity rooms). Finally, a range of analysis metrics can be superimposed as colors on floorplans, including density, footfall and utilization.

These widgets allow users to compare the results they are most interested in and allows them to, for example, balance between costs and waiting times. The use of trace recording provided by SmartMove allows users to save the people movements for a given scenario to review them at a later stage. These trace files contain the movements people made for each second of simulation; from which utilization, wait time and occupancy data can be extracted. Trace files can also be combined for analysis, allowing users to compare scenarios, layouts and interventions on the same set of result metrics for easy comparison. Figure 1 shows the dashboard set up with default widgets for model, population and process simulation for an emergency department. 


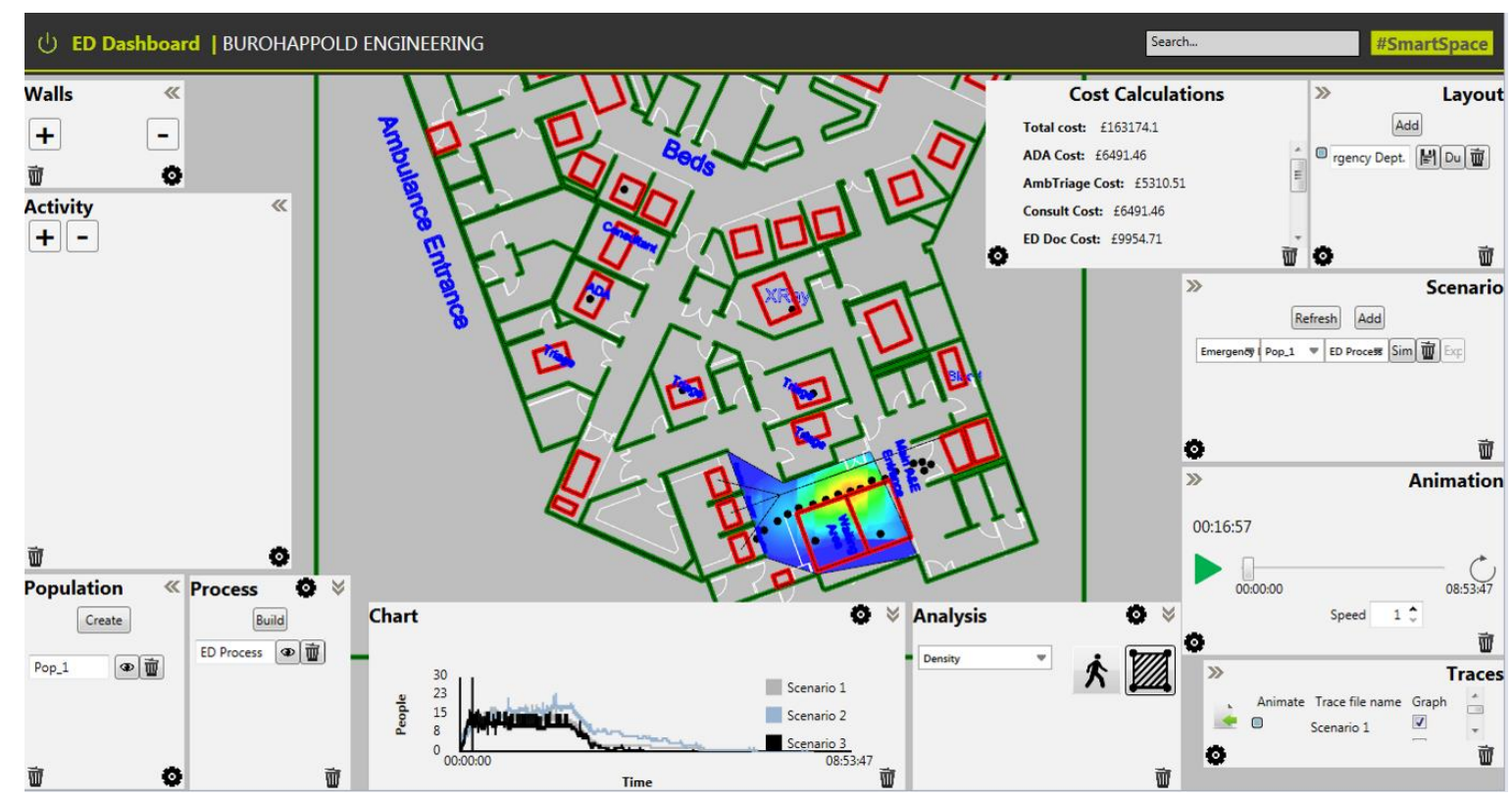

Figure 1 - Dashboard modelling an emergency department.

\section{MODELLING THE EMERGENCY DEPARTMENT}

Emergency departments in hospitals are diverse places of medical care. Treating minor to life-threatening injuries, emergency departments run 24 hours a day, seven days a week, accepting and treating walk-in patients as well as those that arrive by air or road ambulance. In the UK, there is a government target to see, treat or discharge $95 \%$ of emergency department patients within four hours of their arrival (Department of Health 2000; NHS England 2013a). There is a delicate balance between seeing patients in a timely manner, utilizing the clinic space in line with the Carter report (Carter 2016) and keeping costs within reasonable levels. In the example presented here, the dashboard analyzed the existing situation in the Emergency Department of a hospital in the UK, with the standard facility layout, capacities, processes and average patient numbers. This is followed by an analysis of the 'what-ifs', looking at the impact of adding two more triage rooms to the process; followed by looking at the effect of using a rapid assessment and treatment (RAT) model on the department.

\subsection{The Scenarios}

For the demonstration of the dashboard's capabilities three scenarios were defined, simulated and analyzed using the dashboard's widgets as appropriate. The first scenario analyzed the existing situation within the Emergency Department, with the following scenarios modifying an aspect of the layout and patient process from standard triage to rapid assess and treat (RAT). The number of available services, and the service durations, were captured from the Emergency Department and displayed in Table 1. Figure 2 shows the typical patient process for walk-in patients and Figure 3 shows the patient process for ambulance arrivals for both standard triage and RAT processes.

Table 1 - Service times for modelling.

\begin{tabular}{|l|c|c|c|}
\hline \multicolumn{1}{|c|}{ Service type } & Capacity & Service time (standard triage) & Service time (RAT) \\
\hline Ambulance discharge & 1 & 4 minutes & 4 minutes \\
\hline Ambulance triage & 1 & 7.5 minutes & 15 minutes \\
\hline Walk-in triage & 3 & 7.5 minutes & 15 minutes \\
\hline
\end{tabular}


Greenroyd, Hayward, Price, Demian, and Sharma

\begin{tabular}{|l|c|c|c|}
\hline \multicolumn{1}{|c|}{ Service type } & Capacity & Service time (standard triage) & Service time (RAT) \\
\hline ED Doctor & 2 & 20 minutes & 10 minutes \\
\hline Major beds & 22 & 210 minutes & 120 minutes \\
\hline X-Ray & 1 & 8 minutes & 8 minutes \\
\hline Bloods & 1 & 75 minutes & 75 minutes \\
\hline Specialist consultant & 1 & 10 minutes & 10 minutes \\
\hline Streaming process & 1 & 3 minutes & 3 minutes \\
\hline Registration & 2 & 7.5 minutes & 7.5 minutes \\
\hline
\end{tabular}

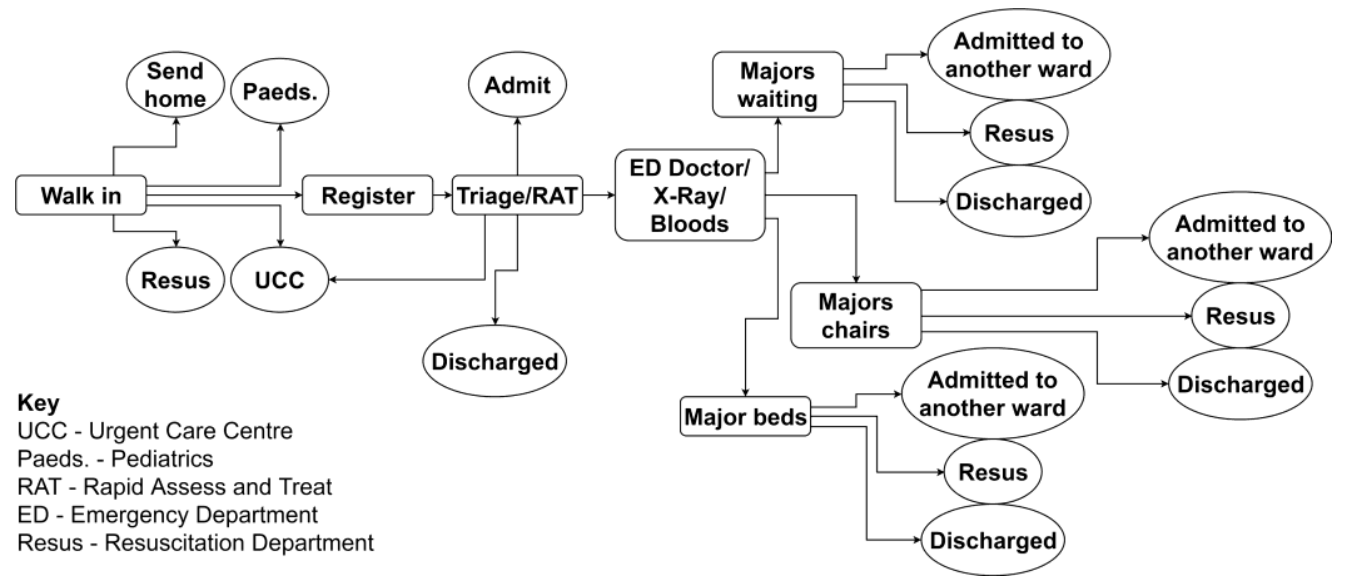

Figure 2 - Process for walk-in patients.

The first scenario visualizes the existing situation within the Emergency Department, using the default layout, service durations, and process. This showcases how the department is functioning with its current demand without making changes. The $3 \mathrm{D}$ visualizations show managers how the department is performing with the patients in mind as well as the department's metrics. Two additional scenarios were then defined to demonstrate the dashboard's functionality. The first additional scenario introduces two additional walk-in triage rooms to the layout, expanding from three to five, and compares the cost, wait times and utilization with the existing scenario.

Table 2 - Scenarios modelled.

\begin{tabular}{|l|l|l|l|}
\hline \multicolumn{1}{|c|}{ Scenario } & \multicolumn{1}{|c|}{ Layout } & \multicolumn{1}{c|}{ Process } & \multicolumn{1}{c|}{ Population } \\
\hline $\begin{array}{l}\text { Scenario 1 }- \\
\text { original situation }\end{array}$ & Original & $\begin{array}{l}\text { Standard } \\
\text { (Figure 2) }\end{array}$ & $\begin{array}{l}89 \text { patients arriving at a constant } \\
\text { rate for } \sim 50 \text { minutes }\end{array}$ \\
\hline $\begin{array}{l}\text { Scenario 2 }- \\
\text { additional triage }\end{array}$ & $\begin{array}{l}\text { Two additional walk-in } \\
\text { triage rooms }\end{array}$ & $\begin{array}{l}\text { Standard } \\
\text { (Figure 2) }\end{array}$ & $\begin{array}{l}89 \text { patients arriving at a constant } \\
\text { rate for } ~ 50 \text { minutes }\end{array}$ \\
\hline $\begin{array}{l}\text { Scenario 3-RAT } \\
\text { process }\end{array}$ & Original & $\begin{array}{l}\text { RAT (Figure } \\
\text { 3) }\end{array}$ & $\begin{array}{l}89 \text { patients arriving at a constant } \\
\text { rate for } ~ 50 \text { minutes }\end{array}$ \\
\hline
\end{tabular}

The final scenario changes the process from traditional "triage" to a "rapid assess and treat" (RAT) process. RAT typically involves senior medical practitioners early in the assessment of patients with 'major' injuries (NHS England 2012) to better move them through the clinical pathway. This approach enables patients with major injuries to be seen by a doctor who can complete an initial assessment and define the care plan for that patient and decide whether they need to be admitted (NHS England 2012), thus allowing for a quicker patient pathway for those that require it. Nurses and junior doctors take over 
to implement the care plan and the patient is moved along the clinical pathway. Table 2 outlines the three scenarios simulated.

\section{RESULTS}

The results of the simulations can be loaded back to the dashboard for comparison between scenarios, allowing the user to compare, contrast and identify aspects for improvement in future simulations. This allows for easy comparison of metrics by users, with the data from each scenario easily accessible and comparable with the widgets provided. For this demonstration, three metrics were core for analyzing the effectiveness of the Emergency Department. First, the time it took to clear the simulation of the patients that arrived at the Emergency Department, i.e. the total simulation time for 89 patients (13 ambulance arrivals and 76 walk-in arrivals) to arrive, be seen and complete their treatment pathway. The second is the occupancy of the waiting area, including the queueing area for registration. The lower the occupancy, the quicker patients are seen and so the more positive the experience is for patients in a low-crowded waiting area. Finally, the waiting time for patients is a key component for patient satisfaction, and while the government target is set that patients should not be waiting more than four hours to be seen, treated or discharged, there is a general advantage to having patients not waiting longer than needed. As such, the wait time analyzed from these scenarios is the total wait time for a patient for any part of their pathway, broken down into the maximum wait time a patient experienced, and the average wait time. Table 3 gives a breakdown of these results available from the HOM dashboard, while Figure 4 provides a chart comparing the occupancy of the waiting room across the three scenarios.

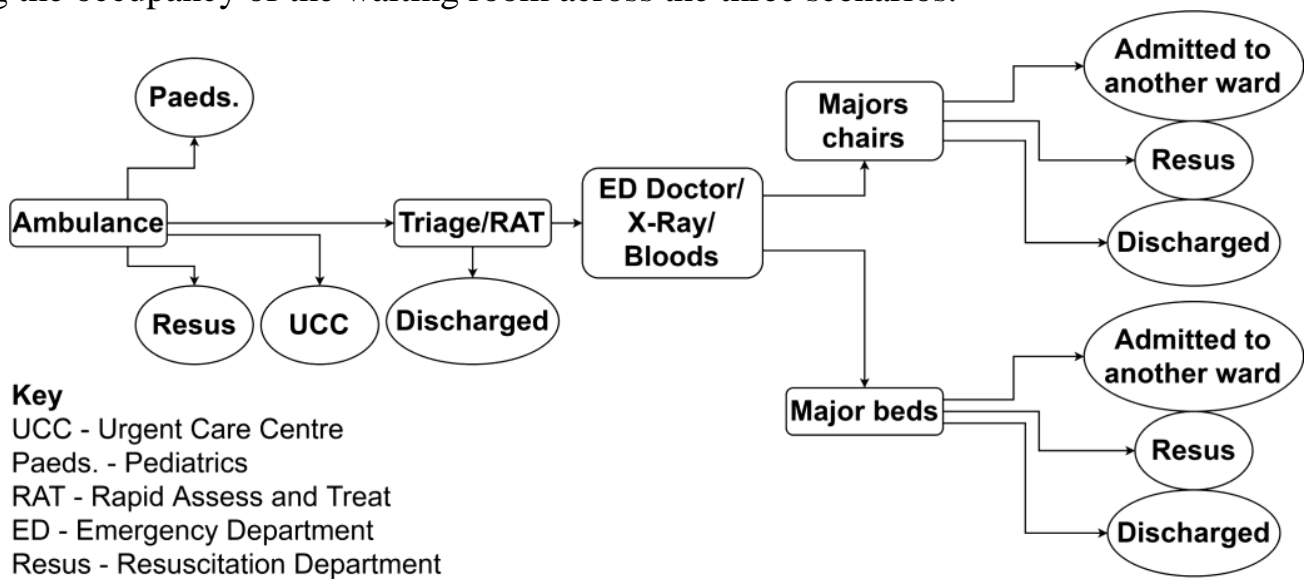

Figure 3 - Process for ambulance arrivals.

Table 3 - Simulation results.

\begin{tabular}{|l|l|l|l|}
\hline \multirow{2}{*}{ Scenario } & \multirow{2}{*}{ Time to complete } & \multicolumn{2}{|c|}{ Wait time } \\
\cline { 3 - 4 } & & Maximum & Average (mean) \\
\hline Scenario 1 & $08: 53: 47$ & $6 \mathrm{hrs} \mathrm{18mins}$ & $1 \mathrm{hr} 7 \mathrm{mins}$ \\
\hline Scenario 2 & $08: 47: 01$ & $5 \mathrm{hrs} 51 \mathrm{mins}$ & $1 \mathrm{hr} 21 \mathrm{mins}$ \\
\hline Scenario 3 & $06: 02: 12$ & $3 \mathrm{hrs} 22 \mathrm{mins}$ & $59 \mathrm{mins}$ \\
\hline
\end{tabular}

The results shown in Table 3 display the evidence for adopting the RAT process in this particular Emergency Department, with improvements to overall patient waiting time (a reduction of 8 minutes on average, and a reduction of 2 hours 56 minutes for the maximum waiting time) and the waiting room occupancy and crowding levels being reduced compared with the standard Triage process. Although Scenario Two reduced the overall maximum waiting time, the average wait time for patients increased as a result of bottlenecks later in the process. Scenario Two reduces the wait time for triage, but with patients 
still requiring later consultation, the average wait time for the patients in the model increases as they wait for services later in the process.

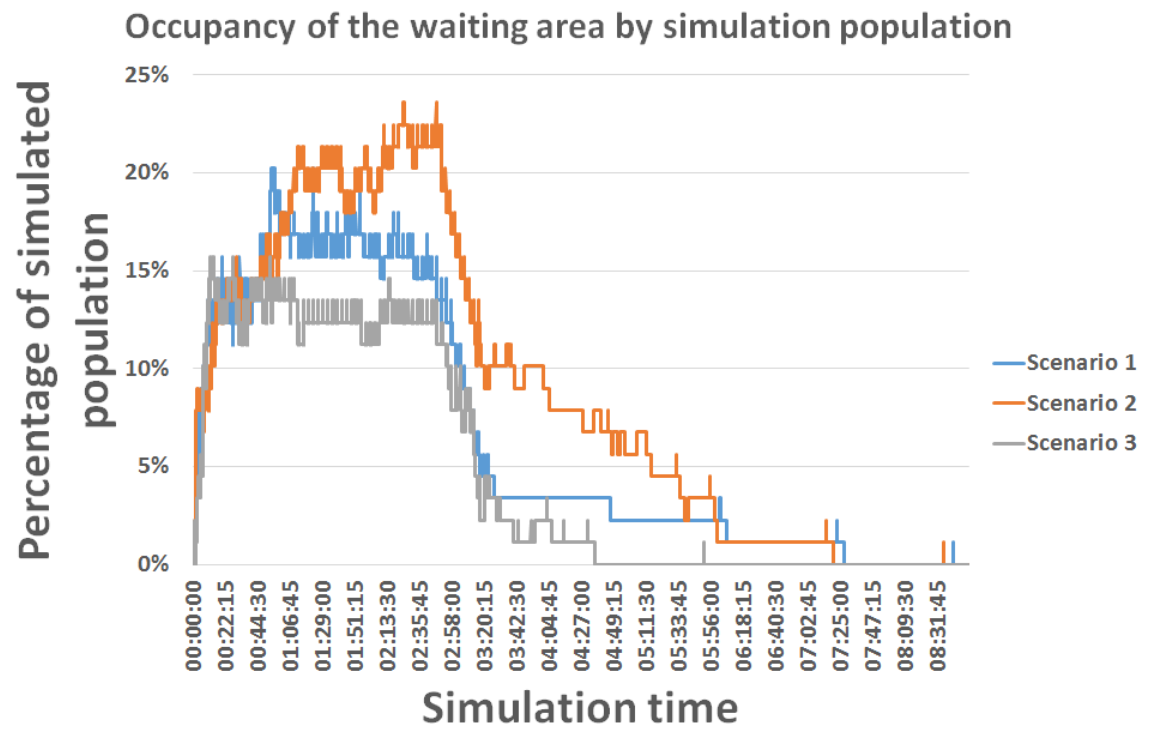

Figure 4 - Waiting area occupancy across the three scenarios.

\section{LIMITATIONS}

Although the dashboard provides users with the ability to balance the cost, patient throughput, waiting times, density levels, and a range of other metrics, it does not provide a measure of the hospital cost as a whole. The calculated cost is for clinic space, as defined by the users, and calculated on square meter operating/construction costs provided by the user. Non-clinical areas, such as store cupboards, administration areas, or corridors are not included in the analysis unless specifically defined by the user. The cost comparisons are performed solely on the defined clinical space and allows the users to balance the cost of construction against the benefits to patients.

Although the HOM dashboard is capable of storing and simulating a number of layouts defined by the user, it does not possess any computational intelligence capabilities to create layouts from a given number of rooms. This could be added in the future for use on new build projects or large renovation projects where the layout may be more flexible.

The initial use of the dashboard may require additional training for users who may not be used to working with CAD models in a 3D space with simulation capabilities. Although the HOM dashboard aims to be as intuitive as possible with small widgets encapsulating relevant functionality, the large choice of widgets available to users may be overwhelming and lead to confusion of how to use the tool to obtain the best output. This can be countered with training and the documentation provided with the dashboard walks users through setting up a simple simulation model and comparing the results. Nevertheless, the dashboard offers users a large range of freedoms in dashboard set up and utilization, ranging from simulation, to comparison, to simple cost comparison functionality.

The simulated outputs of the HOM dashboard offer only a prediction of what may occur within a facility based on the inputs provided by the users. If the inputs are not accurate, then the resultant simulation results will portray an inaccurate report of the facility. It is important therefore to ensure inputs are reasonable, accurate and realistic to prevent this. This can again be countered by training users to use the HOM dashboard appropriately. Alternatively, teams of users can be set up whereby one user validates the inputs of another user prior to simulation being carried out, thus reducing the likelihood of inaccurate inputs being used. However, this would increase staffing costs for each additional person assigned to 
work with the HOM dashboard and so a delicate balance of users would need to be found to prevent increased staffing costs outweighing the benefits of using the HOM dashboard.

Finally, the outputs of the HOM dashboard reported in this paper explore the impact of 89 patients on the Emergency Department in isolation. The simulations does not include patients already in the department prior to the start of the simulation, nor does it add new patients after the first hour. The results and benefits are therefore based on the simulation of those 89 patients only, for comparison across the three scenarios. As emergency departments operate on a 24 hour basis, users may need to include additional patient numbers at the start, and during, the analysis of any observed population.

\section{DISCUSSION}

The HOM dashboard presented here was designed to enable hospital and department managers to understand their hospital/departments and predict the impact of changes to the building. Changes such as the building design, number of attendances, changes to the clinical process, or a mixture of all three, can be analyzed in an environment which is safe for patients before implementation. This helps prevent poor options from being implemented which may negatively impact patient safety, care and/or experience. It may also help prevent unnecessary construction costs for hospitals by providing evidence to argue for, or against, construction. The example within this paper demonstrated that the additional cost of constructing two additional triage rooms would have produced no benefit to patients or the department. Rather, a change in the process provided better benefits compared with the existing situation, and the use of this dashboard to demonstrate that can acquire support from key stakeholders in projects.

The inclusion of simulation allows users to predict what will happen to a facility with respect to the impact on the hospital's users. It allows the NHS to keep at its heart the focal point of its existence, the patients which require its services. It allows the careful balance between patient needs and the needs of the hospital, including pressures from governmental policies and cost saving measures. If the dashboard were focused on only one single aspect of the hospital operation, the delicate balance may be lost. Including facility functionality and patient simulation allows this balance to be maintained.

Future dashboards may be refined further, allowing for the computer to predict, analyze and suggest improvements accordingly. At this stage, the HOM dashboard takes inputs from the user, performs simulations or calculations as required, and returns the outputs of those simulations and calculations in a manner that allows users to strike the right balance and helps to find the most appropriate solution. Future dashboards should incorporate an element of computational intelligence to provide recommendations from a series of simulations, allowing users to compare large numbers of options efficiently. Similarly, future dashboards may incorporate live data links with various systems such as scheduling systems, arrivals records and admissions data sets. Links with live data sources would allow the HOM dashboard to show the current situation to users in real time, while retaining the simulation capabilities that allow users to predict what will happen next within the facility. Live data links also allow the HOM dashboard to make suggestions based on previous data for what best to analyze by the user, such as a changing trend in admissions or seasonal admission variance. Alternatively, combining live data links with computational intelligence would allow the HOM dashboard to simulate various scenarios based on the incoming data and predict which solution for the future would be most optimal for implementation. However, this would require strong calibration of the computational intelligence and sanitization of the live data input to prevent miscalculation or sub-optimal solutions being suggested.

\section{CONCLUSIONS}

This paper has introduced a new dashboard for use by hospital managers to examine existing scenarios, predict the impact of interventions and plan for the future of their facility using the safety of simulation. The use of simulation prediction allows hospitals to explore options in a safe environment to help optimize a solution without negatively impacting patient care or patient safety. The inclusion of cost measuring functions allows the dashboard users to balance patient satisfaction and cost effectiveness for a 
facility. It provides the opportunity to explore different options and obtain evidence to gain stakeholder support prior to the implementation of changes.

The demonstration provided by this paper showcases how one Emergency Department could simulate different options of operation, ranging from increasing triage capacity to adopting a different care process. The analysis showed that constructing additional triage rooms would bring no benefit to the department as the planned demand was not sufficient enough. However, adopting a Rapid Assess and Treat process instead of the standard triage process, allowing patients to be processed more efficiently and provide them with a quicker care program for their needs, provides significant benefits to the department in terms of waiting times and waiting room occupancy/crowding.

Finally, the HOM dashboard can be easily used on an entire hospital model, as well as modelling individual departments for the benefit of the hospital as a whole. The end result of using the dashboard is the user's ability to optimize their facility for a number of metrics, including patient based and governmental metrics, without negatively impacting on the hospital's operations and patient care.

\section{ACKNOWLEDGMENTS}

We would like to thank the Engineering and Physical Sciences Research Council, and Centre for Innovative and Collaborative Construction Engineering at Loughborough University for provision of a grant (number EPG037272) to undertake this research project in collaboration with BuroHappold Engineering Ltd.

\section{REFERENCES}

Al-Araidah, O., A. Boran, and A. Wahsheh. 2012. "Reducing Delay in Healthcare Delivery at Outpatients Clinics Using Discrete Event Simulation.” International Journal of Simulation Modelling 11 (4): 18595. doi:10.2507/IJSIMM11(4)2.211.

Ballard, S. M., and M. E. Kuhl. 2006. "The Use of Simulation to Determine Maximum Capacity in the Surgical Suite Operating Room.” In Proceedings of the 2006 Winter Simulation Conference, edited by B. Lawson, J. Liu, F. Perrone, and F. Wieland, 433-38. Monterey, California: IEEE doi:10.1109/WSC.2006.323112.

Batley, N. J., H. O. Osman, A. A. Kazzi, and K. M. Musallam. 2011. "Implementation of an Emergency Department Computer System: Design Features that Users Value." The Journal of Emergency Medicine 41 (6). Elsevier Inc.: 693-700. doi:10.1016/j.jemermed.2010.05.014.

Brenner, S., Z. Zeng, Y. Liu, J. Wang, J. Li, and P. K. Howard. 2010. "Modeling and Analysis of the Emergency Department at University of Kentucky Chandler Hospital Using Simulations." Journal of Emergency Nursing 36 (4): 303-10. doi:10.1016/j.jen.2009.07.018.

Cabrera, E., M. Taboada, M. Iglesias, F. Epelde, and E. Luque. 2012. "Simulation Optimization for Healthcare Emergency Departments." Procedia Computer Science 9. Elsevier Masson SAS: 1464-73. doi:10.1016/j.procs.2012.04.161.

Carter, P. 2016. "Operational Productivity and Performance in English NHS Acute Hospitals: Unwarranted Variations." London: Department of Health.

Daley, K., J. Richardson, I. James, A. Chambers, and D. Corbett. 2013. "Clinical Dashboard: Use in Older Adult Mental Health Wards." The Psychiatrist 37 (3): 85-88. doi:10.1192/pb.bp.111.035899.

Davis, K., K Stremikis, D Squires, and C Schoen. 2014. "Mirror, Mirror on the Wall, 2014 Update: How the US Health Care System Compares Internationally." New York (NY): Commonwealth Fund 16.

Department of Health. 2000. "The NHS Plan. A Plan for Investment. A Plan for Reform." London: Department of Health.

. 2013. "The NHS Constitution.” London: Department of Health. 
Dowding, D., R. Randell, P. Gardner, G. Fitzpatrick, P. Dykes, J. Favela, S. Hamer, et al. 2015. "Dashboards for Improving Patient Care: Review of the Literature." International Journal of Medical Informatics 84 (2): 87-100. doi:10.1016/j.ijmedinf.2014.10.001.

Fletcher, A, D. Halsall, S. Huxham, and D. Worthington. 2007. "The DH Accident and Emergency Department Model: a National Generic Model Used Locally." Journal of the Operational Research Society 58 (12): 1554-62. doi:10.1057/palgrave.jors.2602344.

Greenroyd, F. L., R. Hayward, A. Price, P. Demian, and S. Sharma. 2016. "Using Evidence-Based Design to Improve Pharmacy Department Efficiency." HERD: Health Environments Research \& Design Journal 10 (1): 130-43. doi:10.1177/1937586716628276.

Halford, G. S, R. Baker, J. E. Mccredden, and J. D. Bain. 2005. "How many Variables can Humans Process?" Psychological Science 16 (1): 70-76. doi:10.1111/j.0956-7976.2005.00782.x.

Harper, P. R., and H. M. Gamlin. 2003. "Reduced Outpatient Waiting Times with Improved Appointment Scheduling: a Simulation Modelling Approach.” OR Spectrum 25 (2): 207-22. doi:10.1007/s00291003-0122-x.

Koopman, R. J., K. M. Kochendorfer, J. L. Moore, D. R. Mehr, D. S. Wakefield, B. Yadamsuren, J. S. Coberly, R. L. Kruse, B. J. Wakefield, and J. L. Belden. 2011. "A Diabetes Dashboard and Physician Efficiency and Accuracy in Accessing Data Needed for High-Quality Diabetes Care." The Annals of Family Medicine 9 (5): 398-405. doi:10.1370/afm.1286.The.

Lee, S., D. Min, J. Ryu, and Y. Yih. 2013. "A Simulation Study of Appointment Scheduling in Outpatient Clinics: Open Access and Overbooking." Simulation 89 (12): 1459-73. doi:10.1177/0037549713505332.

Leskovar, R., R. Accetto, A. Baggia, Z. Lazarevič, G. Vukovič, and P. Požun. 2011. "Discrete Event Simulation of Administrative and Medical Processes." Zdravniski Vestnik 80 (5).

McMenamin, J., R. Nicholson, and K. Leech. 2011. "Patient Dashboard: the Use of a Colour-Coded Computerised Clinical Reminder in Whanganui Regional General Practices." Journal of Primary Health Care 3 (4): 307-10.

Mesabbah, M., and A. Arisha. 2016. "Performance Management of the Public Healthcare Services in Ireland: a Review." International Journal of Health Care Quality Assurance 29 (2): 209-35. doi:10.1108/09526860710819440.

NHS England. 2012. "Rapid Assessment and Treatment Models in Emergency Departments." London: NHS England.

—. 2013a. "NHS England: Improving A\&E Performance.” London: NHS England.

_. 2013b. "The NHS Belongs to the People: a Call to Action." London: NHS England.

Nicholson, D. 2009. “The Year: NHS Chief Executive's Annual Report 2008/09.” London: Department of Health, 47.

Pauwels, K., T. Ambler, B. H. Clark, P. LaPointe, D. Reibstein, B. Skiera, B. Wierenga, and T. Wiesel. 2009. "Dashboards as a Service: Why, What, How, and What Research is Needed?" Journal of Service Research 12 (2): 175-89. doi:10.1177/1094670509344213.

Petersen, D. 2002. Risk Communication in Action: Environmental Case Studies. DIANE Publishing.

Quevedo, V., and J. Chapilliquén. 2015. "Modeling a Public Hospital Outpatient Clinic in Peru Using Discrete Simulation." ICORES, 389-94.

Sharma, S., and A. Fisher. 2013. "Simulating the User Experience: Design Optimisation for Visitor Comfort." Architectural Design 83 (2): 62-65. doi:10.1002/ad.1555.

Stadler, J. G., K. Donlon, J. D. Siewert, T. Franken, and N. E. Lewis. 2016. "Improving the Efficiency and Ease of Healthcare Analysis through Use of Data Visualization Dashboards." Big Data 4 (2): 129-35. doi:10.1089/big.2015.0059.

Vahdatzad, V., and J. Griffin. 2016. "Outpatient Clinic Layout Design Accounting for Flexible Policies." In Proceedings of the 2016 Winter Simulation Conference, edited by P. Frazier, T. Roeder, R. 
Greenroyd, Hayward, Price, Demian, and Sharma

Szechtman, and E. Zhou. 3668-69. Arlington, Virginia: IEEE Press. doi:10.1109/WSC.2016.7822391.

Vanberkel, P. T., and J. T. Blake. 2007. "A Comprehensive Simulation for Wait Time Reduction and Capacity Planning Applied in General Surgery." Health Care Management Science 10 (4): 373-85. doi:10.1007/s10729-007-9035-6.

Varughese, J. S., D. Bouchlaghem, D. Brocklehurst, and S. Sharma. 2010. "People Flow Modeling in Building Design." In Computing in Civil and Building Engineering, Proceedings of the International Conference, 30:59. Nottingham.

Waitman, L. R., I. E. Phillips, A. B. McCoy, I. Danciu, R. M. Halpenny, C. L. Nelsen, D. C. Johnson, J. M. Starmer, and J. F. Peterson. 2011. "Adopting Real-Time Surveillance Dashboards as a Component of an Enterprisewide Medication Safety Strategy." The Joint Commission Journal on Quality and Patient Safety 37 (7): 326-32. doi:10.1016/S1553-7250(11)37041-9.

Werker, G., A. Sauré, J. French, and S. Shechter. 2009. "The Use of Discrete-Event Simulation Modelling to Improve Radiation Therapy Planning Processes." Radiotherapy and Oncology 92 (1). Elsevier Ireland Ltd: 76-82. doi:10.1016/j.radonc.2009.03.012.

Zeng, Z., X. Ma, Y. Hu, J. Li, and D. Bryant. 2012. "A Simulation Study to Improve Quality of Care in the Emergency Department of a Community Hospital." Journal of Emergency Nursing 38 (4). Emergency Nurses Association: 322-28. doi:10.1016/j.jen.2011.03.005.

\section{AUTHOR BIOGRAPHIES}

Fraser L. Greenroyd is a research engineer at Loughborough University working in collaboration with BuroHappold Engineering Ltd. His research interests include computational engineering and the use of computational technology to optimize healthcare designs and processes to improve efficiency and enhance the user experience. His e-mail address is F.Greenroyd@lboro.ac.uk.

Rebecca Hayward is an Associate People Flow Consultant in the Smart Space team of BuroHappold Engineering Ltd. Her interests are in the optimization of spatial designs and operations to enhance user efficiency and experience. Her e-mail address is Becky.Hayward@burohappold.com.

Andrew Price is a Professor of Project Management at Loughborough University. He has over 25 years' experience in design, construction and industry-focused research. His current research interests include innovative design and construction solutions for health and care infrastructure. His e-mail address is A.D.F.Price@lboro.ac.uk.

Peter Demian is a reader in Building Information Management (BIM) at Loughborough University. His research interests are in the development of BIM technologies and knowledge management and humancomputer interaction in construction. His e-mail address is P.Demian@lboro.ac.uk.

Shrikant Sharma is Group Director of the Smart Space team of BuroHappold Engineering Ltd. He has a strong background in computational analytics and has an interest in the visual representation and interrogation of data in accessible formats to aid data understanding in industry. His e-mail address is Shrikant.Sharma@burohappold.com. 